\title{
Impact of converter interface type on the protection requirements for DC aircraft power systems
}

\author{
S. Fletcher, P. Norman, S. Galloway, G. Burt \\ University of Strathclyde
}

Copyright () 2012 SAE International

\begin{abstract}
The utilization of converter interfaces has the potential to significantly alter the protection system design requirements in future aircraft platforms. However, the impact these converters will have can vary widely, depending on the topology of converter, its filter requirements and its control strategy. This means that the precise impact on the network fault response is often difficult to quantify. Through the analysis of example converter topologies and literature on the protection of DC networks, this paper tackles this problem by identifying key design characteristics of converters which influence their fault response. Using this information, the converters are classified based on their general fault characteristics, enabling potential protection issues and solutions to be readily identified. Finally, the paper discusses the potential for system level design benefits through the optimisation of converter topology and protection system design.
\end{abstract}

\section{INTRODUCTION}

The development of more-electric concepts has increasingly seen aircraft designs employ power electronic converter systems for power conversion and conditioning as well as utilizing DC power distribution networks in order to capitalize on efficiency, flexibility and power density benefits $[1,2,3]$. The converter interfaces utilized within these networks can have a significant influence on the fault response of these networks and hence standard approaches to the protection must change in order to accommodate these differences. This influence can vary widely, depending on the topology of converter, its filter requirements and its control strategy and examples of this will be shown in later sections of the paper. As such, the precise impact converters have on the fault response of these networks is often difficult to quantify. This lack of consistency introduces added complexity into the design of effective protection systems and reduces the transferability of a particular protection system design when applied to other networks. The ultimate effect of this is to increase overall system design time, as unique protection solutions must be developed in order to overcome the challenges associated with the integration of new converter technologies into a network.

This paper aims to simplify this design problem by distinguishing different converter topologies based on their general fault response. There are two key behavioral components which influence a converter's response to network fault conditions; first, the extent of the converter's fault current limiting capability and second, the filter requirements of the converter (and hence the natural response of its passive components to a fault). As the work is set in the context of a DC system, the size of the capacitive filters is specifically considered as these have been identified as a source of potentially significant fault current $[4,5,6]$. The following sections will first review some standard converter topologies, highlighting how different aspects of their design can alter their fault response. The protection system challenges for the different converter types are then discussed.

The paper concludes by describing the two key objectives of this work, which the paper moves towards. The first is the consideration of network protection at the converter selection stage of the design process. The paper will highlight that, among other benefits, this can ensure consistency of protection requirements across the network, leading to more effective network protection. The second objective is the development of transferable protection approaches for future aircraft networks, inclusive of the different converter types. Potential solutions to achieve this goal are identified within later sections of the paper. 


\section{REVIEW OF ACTIVE CONVERTER TOPOLOGIES AND TYPES}

In order to establish the different categories of converter which may be utilized within DC networks, this section considers the response of converters at a functional level. It is beyond the scope of the paper to perform a detailed analysis of a specific converter fault response, particularly given the massive number of converter topology options which exist. The intention is rather to draw out the key characteristics of a converter's design which impact its response under network fault conditions, from which any potential protection system issues can be inferred. For this purpose, this section first analyses example converter topologies and control strategies to assess their effect on fault response. Specific categories for converter type are then defined.

\section{SIX-SWITCH VOLTAGE SOURCE CONVERTERS}

The six-switch topology is relatively standard for a Voltage Source Converter (VSC) and this is the topology adopted within much of the literature for DC networks, examples of which are shown in $[4,7,8]$, although it is more limited to use in motor drives within aerospace applications at present [9]. The topology consists of six turn off switches (which are often IGBTs), with antiparallel diodes connected across each of the switches, and a capacitive output filter, as illustrated within Figure 1.

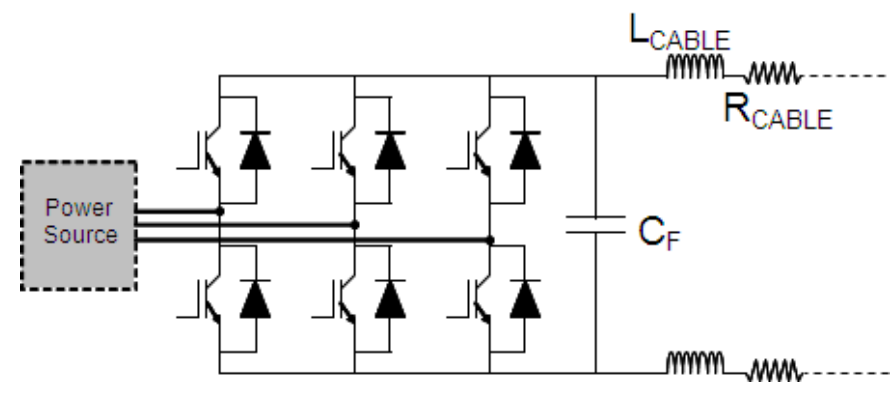

Figure 1 - Standard six switch VSC converter

The topology of the six switch VSC converter is such that significant capacitance is often required to achieve sufficient levels of power quality $[7,10]$. This capacitance, $C_{F}$ within Figure 1, is also required to provide a back-biasing voltage across the antiparallel diodes to prevent conduction under normal operation. However, under DC network fault conditions, this voltage may be lost. Under these conditions, the diodes would begin to conduct and the converter would be unable to block the flow of current to the fault $[8,10]$.

This situation occurs when voltage on the non-network side exceeds the network voltage by more than the diode switch-on voltage. This is illustrated in the simplified circuit in Figure 2.

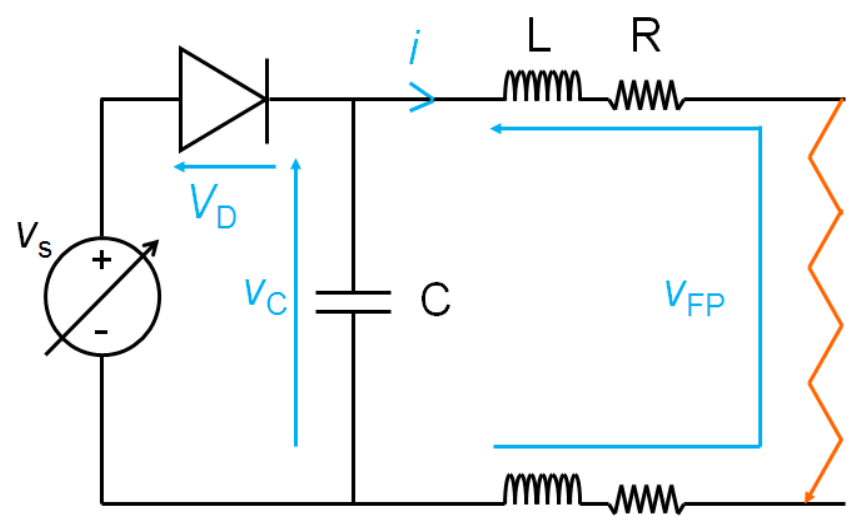

Figure 2 - Simplified circuit highlighting the antiparallel diode conduction path and back biasing voltages

From Figure 2, the fault conditions under which diode conduction occurs are

$$
Z_{F P} \times I_{\mathrm{CONV}} \leq V_{\mathrm{S}}+V_{\mathrm{D}}
$$

Page 2 of 13 
where $Z_{F P}$ is the impedance of the fault path (including the line and fault), $I_{C O N V}$ is the converter output current and $V_{D}$ is the on-state voltage of the antiparallel diodes in the converter. Equation (1) highlights that the level at which the converter can continue to control current is highly dependent on the impedance of the fault path. For compact aircraft systems with relatively low voltage drops on the conductors, it is clear that this control would be lost in the majority of fault conditions, and would only be retained where the fault itself had reasonably large impedance. This is particularly problematic as the fault current withstand of VSCs is low compared to more robust thyristor based converter topologies [4,7], therefore current must be limited or interrupted much more quickly to prevent damage to internal components when supplying fault current. These types of issues are discussed in more detail within later sections.

\section{TWO SWITCH BUCK-BOOST DC/DC CONVERTER}

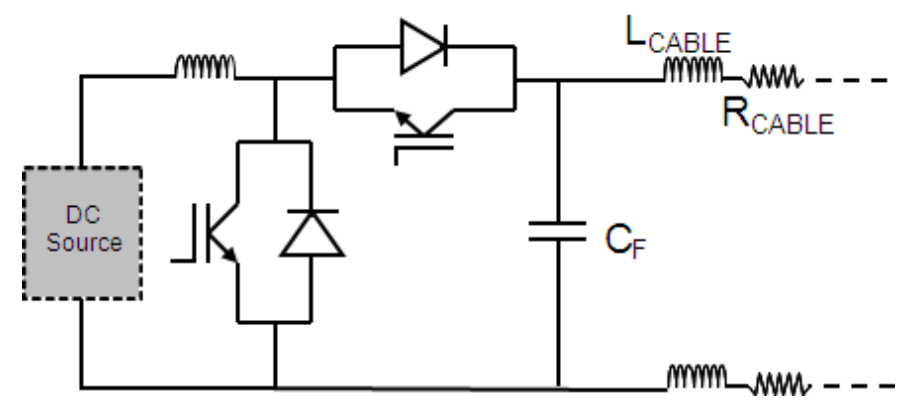

Figure 3 - Two switch buck-boost DC/DC converter topology [11, 12]

Figure 3 illustrates the topology of the conventional two switch buck-boost DC/DC converter, a converter which has been proposed for use to interface energy storage elements to a DC network in electric vehicle and aerospace applications [11, 12]. This type of converter has similar characteristics to that of the VSC, requiring large filter capacitance (which can be prohibitively large in some cases [13]) and containing antiparallel diodes. As with the VSC, the location of these antiparallel diodes means that if output voltage was lost, the diodes would conduct current. As the converter switching elements would be bypassed, it could no longer control current magnitude.

\section{INTERLEAVED DC/DC CONVERTER}

The design of the interleaved DC/DC converter has evolved from the conventional two switch converter and enables a reduction in converter size and an increase in efficiency and reliability [13]. An example the interleaved DC/DC converter topology is illustrated in Figure 4.

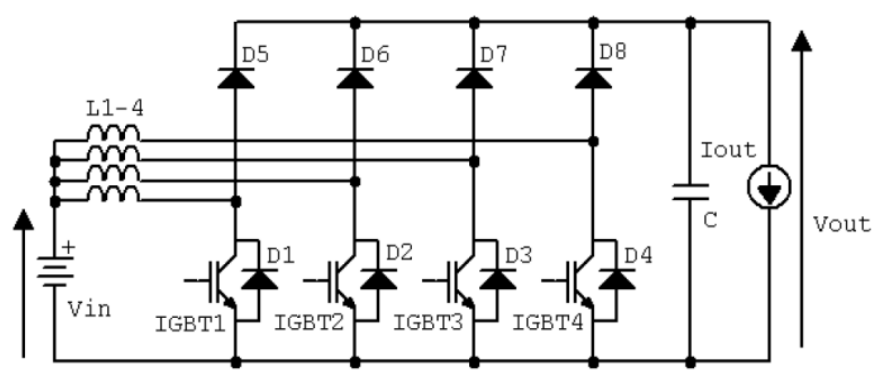

Figure 4 - Interleaved 4-channel boost DC/DC converter [14]

The key benefits of the interleaved design are derived from the converter's parallel switches and coupled inductors, which reduce the burden on the capacitive output filter, enabling a reduction in its size. The extent to which these filtering requirements can be reduced is partly dependent on the number of parallel channels utilized as an increase the number of channels will decrease output voltage ripple [14]. The performance improvement through the use of an interleaved topology does however come at the cost of additional inductors and power switching devices [13]. Furthermore, the location of the diodes within this converter topology is such that they would be unable to block current during loss of DC side voltage, as with the previous converter types. 


\section{CROWBARRING}

One means of limiting current output when antiparallel diodes exist within the converter is to utilize a crowbar. A crowbar can be applied by either activating a physical crowbar on the source side [15] or by turning on the active switches within a leg of the converter to create an internal crowbar [16], effectively providing the converter will current limiting capability. The degree to which the crowbar could limit fault current would depend on the impedance of the crowbar itself and that of the fault path. Application of a crowbar would likely to lead a scenario where current is split between the crowbar and the fault. In any case, it is essential that the crowbar is capable of handling high currents for a sustained period, which may require the use of highly rated switches [16]. This requirement also applies to the source, which would be required to sustain an effective short circuit across its terminals without causing itself damage.

\section{ANTIPARALLEL DIODE REPLACEMENT}

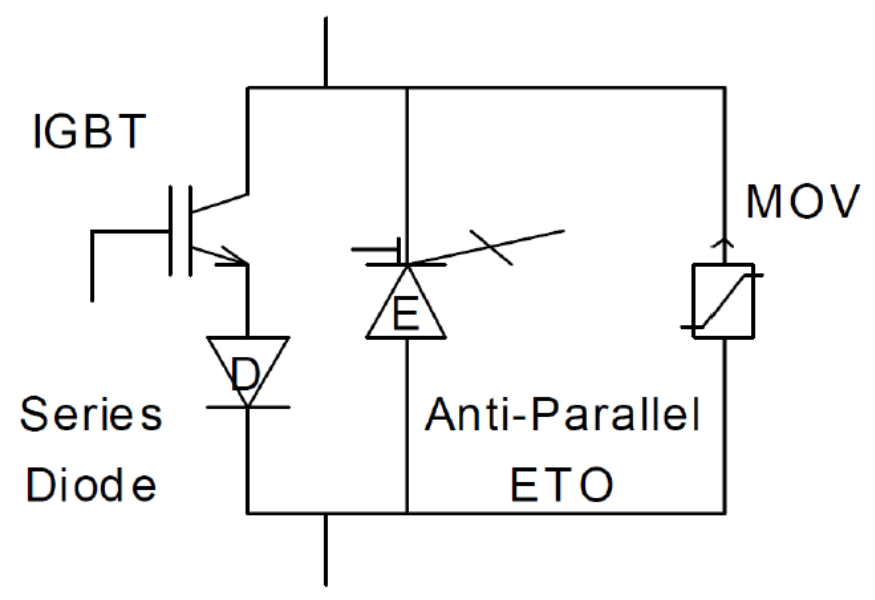

Figure 5 - VSC switch Realization with IGBT and Anti-Parallel ETO Device [17]

Figure 5 illustrates a modified version of a single switch segment of the standard VSC design, proposed for use within [17]. The design has been modified to replace the antiparallel diode with a turn-off device; in this case an emitter turn-off (ETO) device has been selected, the design of which is described in [18]. In addition to this, a metal-oxide varistor (MOV) has been connected in parallel to suppress voltage transients across the converter during switching events. The primary purpose of replacing the antiparallel diode is to prevent the constant conduction of these diodes following the loss of the back-biasing DC voltage, with the usually turned on ETO giving the converter the capability to limit or interrupt current, albeit at the cost of increased conduction loss in the antiparallel diode path. As the capacitive filter is located on the DC side of the converter, the discharge phase the fault response remains, however the topology change enables control of the secondary fault infeed from the AC side.

Whilst this topology would add some cost and complexity to the converter design compared to the standard VSC, it does serve as an example of how a converter can be used to limit current into a faulted DC network.

\section{MULTILEVEL AND MODULAR MULTILEVEL CONVERTER TOPOLOGIES}

The application or proposed application of multilevel converters has so far tended towards medium or high voltage applications, such as the multiterminal DC schemes presented within [19 - 24]. One of the main benefits of multilevel converter designs is the capability to produce a DC output with low harmonic content, though this is at the cost of additional switch components. This enables filter requirements to be minimized, potentially alleviating the protection problems which stem from the converters natural response. Modular multilevel designs, an example of which is illustrated within Figure 6, take this a step further by removing the central bus capacitance and instead distributing it between the different converter levels. In certain module configurations, this enables blocking of the capacitive discharge part of the fault response completely. However, the potential for application of these types of converters to lower voltage and more compact applications remains unclear, with cost, complexity and power density likely to count against their utilization in the short to medium time scales. These converters do however provide an example of a design which has minimal filter requirements and current limiting capability. 


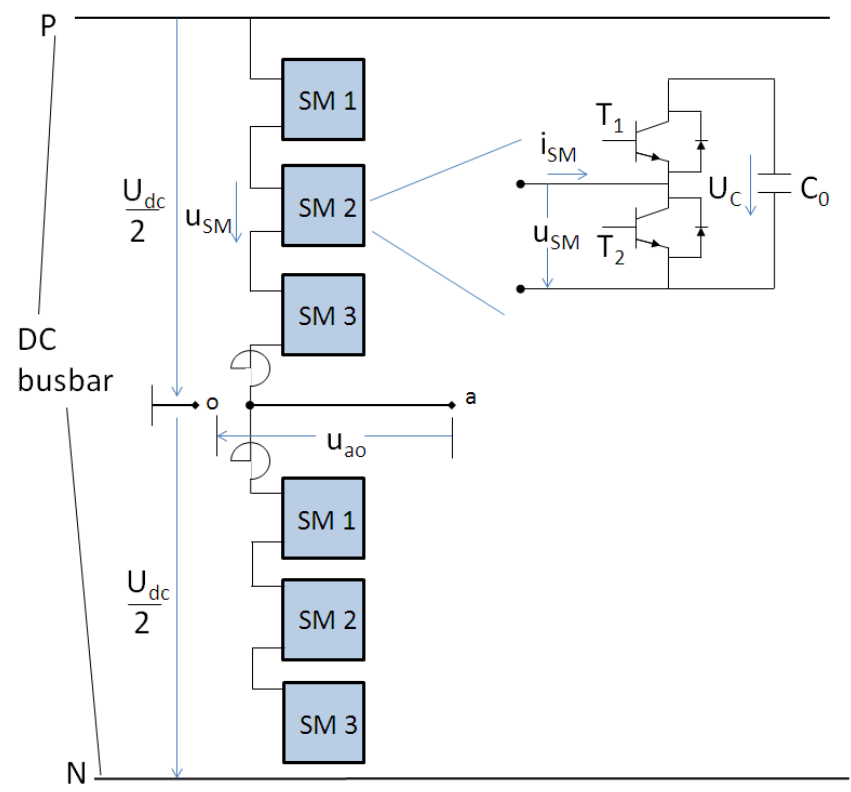

Figure 6 - Single phase diagram of the modular multilevel VSC [24]

\section{CONVERTER TYPE CATEGORISATION}

From the review within previous sections of the key behavioral components, converter type has been classified in four ways:

1. Non-current limiting - high capacitance

2. Current limiting - high capacitance

3. Non-current limiting - low capacitance

4. Current limiting - low capacitance

Examples of these converter types are shown above with standard VSCs fitting into the 'non-current limiting - high capacitance' category, whereas a topology such as the interleaved DC-DC converter is representative of a 'non-current limiting - low capacitance' converter. Within these categories, the terms 'high' and 'low' capacitance are somewhat imprecise, however the intention is to capture cases where, and where not, the current contribution from the capacitive filter significantly contributes to the overall fault current. From the examples above, 'high capacitance' is in the order of millifarads and 'low capacitance' is in the order of microfarads. The unique set of challenges associated with their protection of each of these four converter types is illustrated in the following section.

\section{IMPACT OF CONVERTER INTERFACE TYPE ON THE PROTECTION REQUIREMENTS}

As the previous section highlights, changes in converter topology can affect the fault response in a number of ways. The following sections will generalize this impact under the derived converter categories, assessing both protection issues which may result from a specific converters use and potential protection solutions. To contextualize the discussion in following section, Figure 7 illustrates an example section of DC network for an aircraft electrical system. This figure illustrates possible locations and connection options for the generation and load systems interfaced to the network via active converters and their associated filter components. 


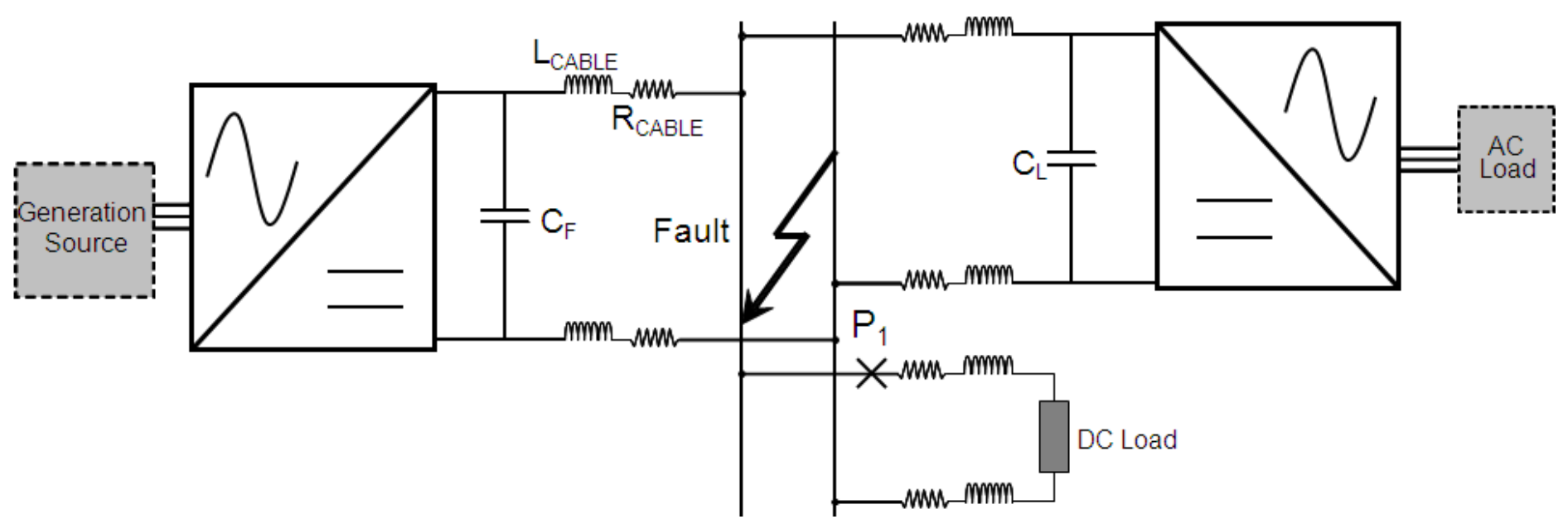

Figure 7: Example aircraft network section with active converters used to interface generation and loads

NON-CURRENT LIMITING - HIGH CAPACITANCE CONVERTER TYPES

\section{Protection issues}

Prior work by the authors has assessed the potential protection issues associated with the non-current limiting - high capacitance converter type $[6,25,26]$. These issues can be illustrated through the plot shown in Figure 8, which provides an example fault response of a converter interface within a 270VDC UAV network, such as that shown in Figure 7. Full details of component parameters for this simulation can be found within [25].

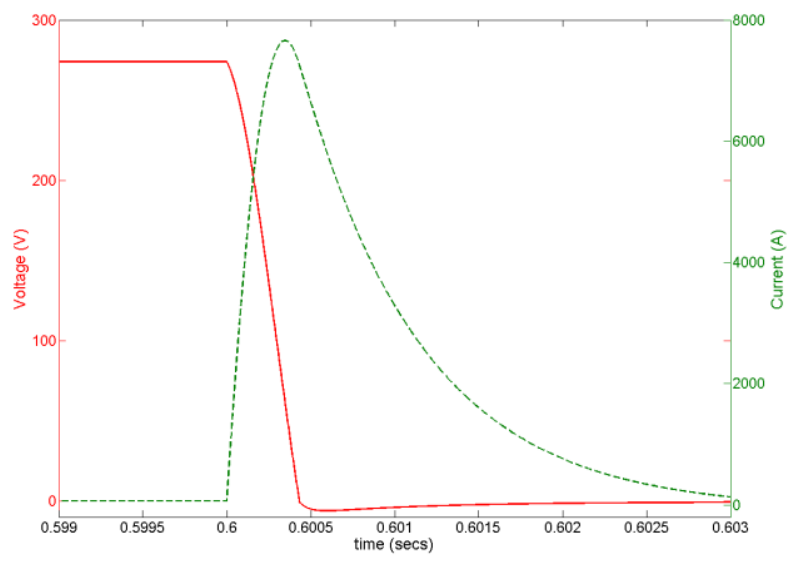

Figure 8 - Filter capacitor voltage (solid line) and current (dashed) response to a short circuit fault applied at 0.6s [25]

Within Figure 8, the current and voltage responses can cause a number of network protection issues. These issues include:

- High magnitude current discharge of capacitors can potentially damage sensitive components in the fault path or even the capacitors themselves $[4,18]$.

- A large difference between the initial fault current peak, as produced by the discharge of filter capacitors, and sustained fault current produced by converter interfaced generators can cause significant problems for the coordination of the network protection $[5,26]$.

- Rapid undervoltage conditions created by the discharging filter capacitors has the potential to cause internal protection of power electronic converters throughout the network to operate [26, 27], resulting in poor protection selectivity and the propagation of fault effects.

- Oscillations between inductance and capacitance in the circuit can cause the voltage across the converter's filter capacitor to become negative. This has the potential to cause significant currents to flow through the converter's antiparallel diodes, 
presenting a risk of the diodes being damaged $[6,10]$. These aspects of the fault response are shown more clearly in Figure 9, which illustrates the current through antiparallel diodes following a voltage reversal on capacitor $\mathrm{C}_{\mathrm{F}}$ in Figure 7 (using the same network parameters and fault conditions as within Figure 8).
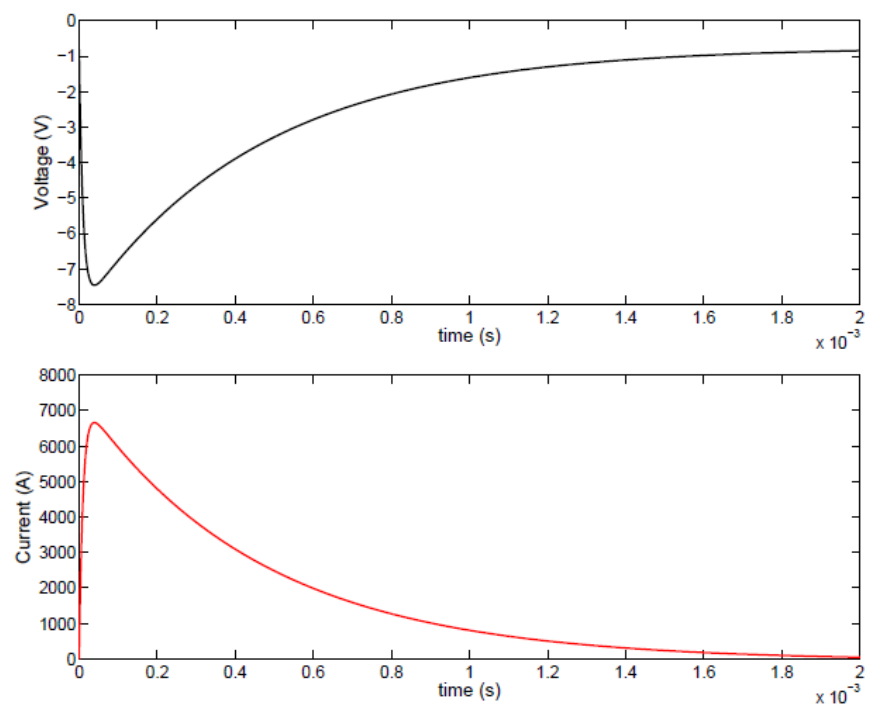

\section{Figure 9 - (a) Voltage across the converter's terminals and (b) subsequent current through the antiparallel diodes, following a fault at time $=0 \mathrm{~s}$}

For networks containing these converter types to be effectively protected, these issues must be accommodated. Potential options to overcome these significant challenges are outlined in the following section.

\section{$\underline{\text { Potential solutions }}$}

The protection issues outlined in the previous section are very challenging to overcome. Whilst there are examples within literature which tackle aspects of the problem, a single solution does not yet exist. One potential solution, as proposed in [5], looks to overcome the fault detection and discrimination issues by operating protection on the sustained fault current input from the network converters. This however requires network components and protection devices to withstand the initial fault transients as well as extended fault clearance times, and so necessitates the use of more robust converter switches and diodes and protection devices. This would potentially impact the overall space and weight of the electrical system and increase energy dissipated at the point of fault. An alternative solution, as proposed within [4], is to operate protection during initial transients, based on instantaneous overcurrent trip at a capacitor's output, in order to protect capacitors and other network components. However, the solution as proposed is at the expense of wider fault discrimination, which would not be acceptable within all applications. Potential opportunities to implement this transient interruption approach in a more coordinated manner are discussed by the authors of this paper within [6] and [26] and this is a continuing area of research.

\section{NON-CURRENT LIMITING - LOW CAPACITANCE CONVERTER TYPES}

\section{$\underline{\text { Protection issues }}$}

Due to the low capacitive filter requirements of the converter type considered within this section, the potential for component damage and poor protection system discrimination as a result of large capacitive discharge currents is less of an issue. However, one transient protection issue that this converter type has in common with the higher capacitance converter types is the potential for voltage reversal if DC side faults are not cleared within an adequate time frame. In fact, the lower capacitance at the converter terminals may accelerate the occurrence of the voltage reversal scenario as less transient voltage support is offered to the DC network. The requirements placed on the network protection due to these conditions will depend on a number of factors, such as the exact converter topology and tolerance of diodes contained within the converter. However, results presented in previous sections highlight that voltage reversal has the potential to damage converters and so steps should be taken to protection against this condition where necessary. 
One further protection consideration which must be made when utilizing low capacitance converters is their susceptibility to overvoltage transients. Previous research by the authors has shown how the redistribution of stored inductive energy when interrupting high fault currents can lead to significant post-fault voltage transients [6]. As an example of this, Figure 10 illustrates the results of a case study on a 270VDC network similar to Figure 7 (the full details of which are shown in [6]), where circuit breakers (such as P1 on the DC load branch in Figure 7) were set to operate for a range of fault clearance times following the occurrence of a fault. The figure plots maximum transient voltage magnitude across capacitance $\mathrm{C}_{\mathrm{L}}$ at the load's converter interface (the capacitance of which was significantly less than that of the generator's converter) and fault current at the time of protection operation against circuit breaker operating time.

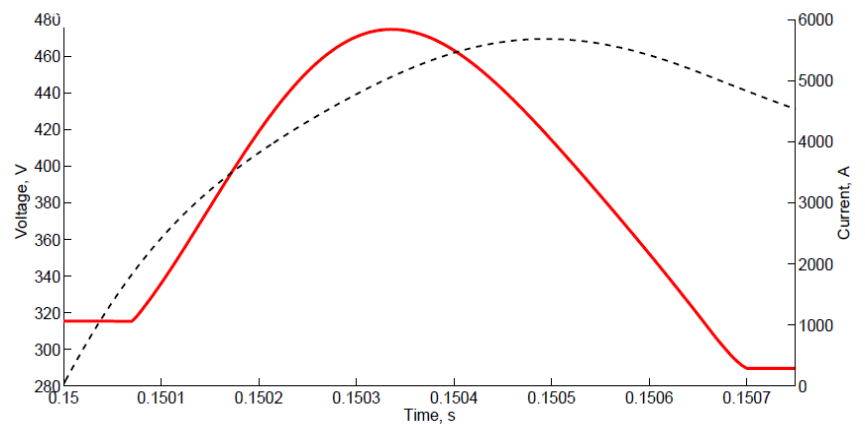

\section{Figure 10 - Maximum voltage transient (solid line) caused by circuit breaker operation after a short circuit fault at 0.15 s compared to current being interrupted (dashed line) [6]}

Figure 10 illustrates that in this case, operation of protection may cause voltage spikes of up to 1.75 times the nominal system voltage at load converter terminals. For these scenarios it is important to ensure that these converters are neither damaged by these network transients nor caused to disconnect from the network due to overvoltage protection operation. Either of these events could result in the effects of the fault expanding beyond the initial point of inception.

\section{$\underline{\text { Potential solutions }}$}

Whilst the lower capacitance of the converter filter has made the initial fault transient less severe, the potential for voltage reversal transients to occur across the converter terminals still remains. Therefore the requirements of the protection system remain similar to that previous; either design the system to withstand the expected transients, which in the case of voltage reversal could involve using diodes with higher rated transient current withstand, or operate protection to isolate the fault before the severe transient develops, which would be in a similar time frame to that discussed above.

Figure 10 highlighted that operating protection in the timescales in which to prevent voltage reversal may in fact lead to overvoltage transients, although these two issues would only combine in this manner if both 'high' and 'low' capacitive sources existed within the network. Potential solutions to avoid these overvoltages, as discussed in [6], include the use of voltage suppression devices and the utilization of converter components that can withstand these voltage transients. More active solutions also include the manipulation of circuit breaker operating time to avoid conditions where its operation would cause significant voltage transients. However, this solution would only be viable where fault current is variable with time, such as with the output of a capacitor.

\section{CURRENT LIMITING - HIGH CAPACITANCE CONVERTER TYPES}

\section{$\underline{\text { Protection issues }}$}

At a high level, the protection issues which exist for this converter type are similar to those of the 'non-current limiting - high capacitance' converters. As high capacitance is common to the two converter types, there is also the potential for high magnitude current transients immediately following fault inception as the current flow from the capacitive source is unaffected by converter topology. Another issue this converter type has in common with the non-current limiting case is the potentially large difference between the initial fault current peak and the sustained fault current produced by the converter. The extent to which this differs between the two cases depends both on the level to which current is limited and the capacity and fault response of the source connected at the AC side of the converter. However, it is anticipated that any fault discrimination issues would be more pronounced where a converter was limiting through-current. 
One area where a current limiting topology may be particularly beneficial is in its response to voltage reversal effects, although these benefits would depend on how current limiting is realized. For the example topology shown in Figure 5, the replacement of antiparallel diodes with ETOs would enable the current induced by the negative voltage to be interrupted when desired.

\section{$\underline{\text { Potential solutions }}$}

As discussed previously, no single definitive solution yet exists for the protection of networks containing large capacitive filters. For this converter type it would be desirable to operate protection on the capacitive current, both to mitigate the impact of this transient and to avoid discriminating fault location based in the limited converter contribution, as this could lead to the fault remaining on the system for longer than necessary. As before, options to achieve this performance are discussed within [6].

\section{CURRENT LIMITING - LOW CAPACITANCE CONVERTER TYPES}

\section{$\underline{\text { Protection issues }}$}

The fault response of 'current limiting - low capacitance' converter types is the least severe of all the converters considered, and despite initial capacitive discharge and voltage reversal conditions still occurring, these should not cause significant issues for network protection. A challenge which does remain is the accurate and timely discrimination of fault location. This is a particular issue for this converter type due to the lack of any significant fault current source which would indicate the presence or location of a fault [28].

One additional issue is the potential for overvoltages due to fault clearance transients, as reported previously. However, the probability of these would be reduced compared to the 'current limiting - low capacitance' case due to the expected lower breaking currents.

\section{$\underline{\text { Potential solutions }}$}

Given that this converter type places no unique demands on the protection system, such as the necessity to mitigate high magnitude transients, it is anticipated that standard protection approaches could be utilized. The only limit on this would be whether overcurrent based approaches could achieve acceptable detection times under the low fault current conditions. If not, more robust approaches, such as current differential protection may be required [28].

\section{TRADE OFF BETWEEN CONVERTER INTERFACE AND PROTECTION SYSTEM DESIGN}

One general theme coming out of the previous sections is that the more complex the converter design, i.e. those with the greater number of components and switches, the lower the requirements on the protection system. This presents an interesting system design trade off, where the size and rating of protection devices would vary with that of the converter type within the network. Table 1 and Table 2 attempt to summarize these protection system and converter design factors respectively. These are particularly relevant given the number of competing design objectives within aircraft power systems [29] and the continued need to increase overall system efficiency within future platforms whilst maintaining a very safe, redundant and reconfigurable network design. 
Table 1 - Summary of protection issues associated with the different converter types

\begin{tabular}{|c|c|c|}
\hline High \\
capacitance & $\begin{array}{c}\text { Non-current } \\
\text { limiting } \\
\text { detection and } \\
\text { interruption or high } \\
\text { system tolerance }\end{array}$ & $\begin{array}{c}\text { Current Limiting } \\
\text { of voltage } \\
\text { reversal are } \\
\text { minimised }\end{array}$ \\
\hline $\begin{array}{c}\text { Low } \\
\text { capalt discrimination } \\
\text { challenging }\end{array}$ & $\begin{array}{l}\text { 1. Greater voltage } \\
\text { oscillation and } \\
\text { potential for } \\
\text { voltage reversal }\end{array}$ & $\begin{array}{c}\text { 1. Fault } \\
\text { discrimination } \\
\text { challenging }\end{array}$ \\
& $\begin{array}{l}\text { 2. Susceptible to } \\
\text { overvoltage } \\
\text { transients }\end{array}$ & \\
\hline
\end{tabular}

Table 2 - Summary of converter design requirements associated with the different converter types

\begin{tabular}{|c|l|c|}
\hline & Non-current limiting & $\begin{array}{c}\text { Current } \\
\text { Limiting }\end{array}$ \\
\hline $\begin{array}{c}\text { High } \\
\text { capacitance }\end{array}$ & $\begin{array}{l}\text { 1. Simplest design } \\
\text { 2. High withstand } \\
\text { requirement }\end{array}$ & $\begin{array}{c}\text { 1. Higher switch } \\
\text { count (turn off } \\
\text { freewheel path) } \\
\text { 2. Increased } \\
\text { switching } \\
\text { losses }\end{array}$ \\
\hline Low & $\begin{array}{l}\text { 1. Minimal voltage } \\
\text { support on bus } \\
\text { requires tight control }\end{array}$ & $\begin{array}{l}\text { 1. Higher switch } \\
\text { and component } \\
\text { count }\end{array}$ \\
& $\begin{array}{c}\text { 2. High withstand } \\
\text { requirement }\end{array}$ & \\
& 3. Higher switch and \\
& component count & \\
\hline
\end{tabular}

In order to capitalize on any design benefits associated with optimizing the converter and protection system design it is first necessary to quantify the impact of different protection operating strategies on the system. One example of this would be consider the difference between the design requirements for implementing fast acting protection on the 'non-current limiting - high capacitance' converter types and the more standard protection requirements for the 'non-current limiting - high capacitance' converters. Quantification of such properties would enable network protection to feature at earlier stage of the design process and be considered in a more measured way when making network design choices and this is an important area of future research. 


\section{TRANSFERABLE PROTECTION SYSTEM DESIGN SOLUTIONS}

Whilst there is inconsistency in the fault response of different converter types, a number of the protection issues caused are common across these converters, as Table 1 in the previous section highlights. This presents an opportunity to develop sets of common protection system solutions for the different converter types, albeit scaled to different power levels, rather than considering them in isolation.

The objective of this approach would be to more easily assess the protection requirements of new converter technologies within a network; more easily integrate these converters into a network and ultimately decrease overall design time. These objectives are analogous to those of the Power Electronic Building Block (PEBB) concept, which looks to standardize the application of power electronic interfaces within shipboard applications [30]. A highly simplified process for achieving this is illustrated in Figure 11, where a new converter topology would be categorized as discussed previously, from which any protection considerations would be immediately highlighted and appropriate solutions identified.

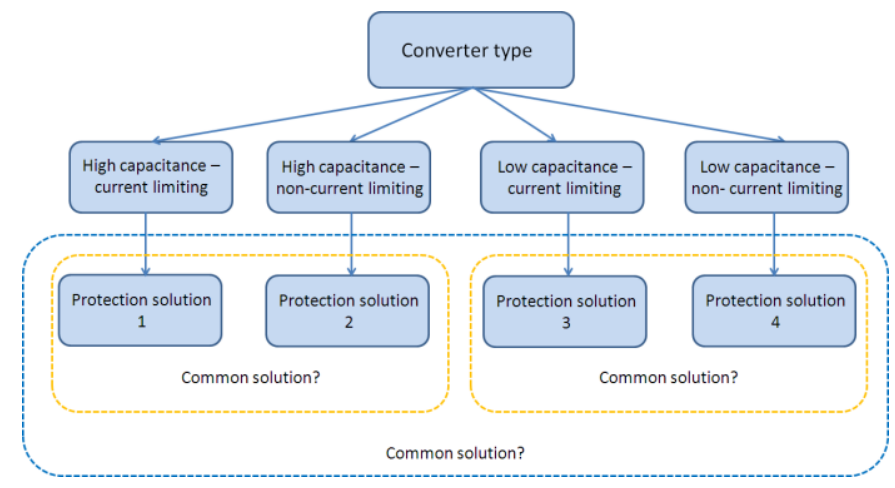

Figure 11: Flowchart to identify appropriate protection solutions depending on converter type

Some potential solutions have already been highlighted within previous sections which could be used to begin populating this diagram; however a more detailed review of current solutions as well as testing of more novel approaches is required for this to be a useful tool going forward. Importantly these solutions must also take account of the requirements of different applications, where, for example, the cost of one protection approach may not be justifiable for all applications.

A final consideration is protection of networks with mixed converter types within a network. The paper has focused on the issues associated with a single converter type within a network, and therefore this analysis would need to be expanded ensure effective protection operation across the system.

\section{CONCLUSIONS}

Given the increased penetration of converter interfaced sources and loads within aircraft power systems it is essential that their impact on a network's fault response and protection scheme is well understood. Through the analysis of example converter topologies this paper has identified key design characteristics of converters which influence their fault response and protection requirements. Categorizing the converters based on these characteristics enables the protection issues associated with each converter type to be generalised, clarifying any similarities or distinctions between the converter types. This also provides opportunities for common protection system solutions to be explored. The paper highlights that a trade-off often exists between optimal converter topology and protection system design, where increased complexity in one may simplify the other. To establish the potential for system wide optimization based on these trade-offs, the quantification of these properties is an important area of future research.

\section{REFERENCES}

1. Emadi, K., Ehsani, M. "Aircraft power systems: technology, state-of-the-art, and future trends", IEEE Aerosp. Electron. Syst. Mag., 2000, 15, (1), pp. 28-32

2. J. Rosero, J. Ortega, E. Aldabas, and L. Romeral, "Moving towards a more electric aircraft," Aerospace and Electronic Systems Magazine, IEEE, vol. 22, no. 3, pp. 39, March 2007.

Page 11 of 13 
3. Bennett, J., Mecrow, B., Atkinson, D., Maxwell, C., Benarous, M., "A fault tolerant electric drive for an aircraft nose wheel steering actuator", Fifth IET Conf. on Power Electronics, Machines and Drives, April 2010

4. M. E. Baran and N. R. Mahajan, "Overcurrent protection on voltage-source-converter-based multiterminal de distribution systems," Power Delivery, IEEE Transactions on, vol. 22, no. 1, pp. 406-412, Jan. 2007.

5. R. Cuzner and G. Venkataramanan, "The status of DC micro-grid protection," in Industry Applications Society Annual Meeting, 2008. IAS '08. IEEE, Oct. 2008, pp. 1-8.

6. S. Fletcher, P. Norman, S. Galloway, and G. Burt, "Determination of protection system requirements for dc unmanned aerial vehicle electrical power networks for enhanced capability and survivability,” IET Electr. Syst. Transp., vol. 1, no. 4, pp. 137-147, 2011.

7. D. Salomonsson, L. Soder, and A. Sannino, "Protection of low-voltage de microgrids," Power Delivery, IEEE Transactions on, vol. 24, no. 3, pp. 1045-1053, July 2009.

8. L. Tang and B.-T. Ooi, "Locating and isolating DC faults in multi-terminal DC systems," Power Delivery, IEEE Transactions on, vol. 22, no. 3, pp. 1877-1884, July 2007.

9. Argile, R.N.; Mecrow, B.C.; Atkinson, D.J.; Jack, A.G.; Sangha, P.; , "Reliability analysis of fault tolerant drive topologies," Power Electronics, Machines and Drives, 2008. PEMD 2008. 4th IET Conference on, vol., no., pp.11-15, 2-4 April 2008

10. J. Yang, J. Fletcher, and J. O'Reilly, "Multiterminal dc wind farm collection grid internal fault analysis and protection design," Power Delivery, IEEE Trans., vol. 25, no. 4, pp. 2308-2318, Oct. 2010.

11. Todd, R., Wu, D., dos Santos Girio, J.A., Poucand, M., Forsyth, A.J., , "Supercapacitor-based energy management for future aircraft systems," Applied Power Electronics Conference and Exposition (APEC), 2010 Twenty-Fifth Annual IEEE , pp.13061312, 21-25 Feb. 2010

12. Arnet, B.J.; Haines, L.P.; , "High power DC-to-DC converter for supercapacitors," Electric Machines and Drives Conference, 2001. IEMDC 2001. IEEE International , pp.985-990, 2001

13. James Scofield, Seana McNeal, Brett Jordan, Hiroyuki Kosai, Biswajit Ray, "Studies Of Interleaved DC-DC Boost Converters With Coupled Inductors", Air Force Research Laboratory reference AFRL-RZ-WP-TR-2011-2061, available online from http://www.dtic.mil/dtic/tr/fulltext/u2/a542736.pdf, accessed 24.5.12.

14. Sakka, M.A.; Van Mierlo, J.; Gualous, H.; , "Efficiency optimization of a 30KW interleaved 4-channels DC/DC converter with variable number of active channels," Power Electronics and Applications (EPE 2011), Proceedings of the 2011-14th European Conference on, vol., no., pp.1-8, Aug. 30 2011-Sept. 12011

15. Wolmarans, J.J.; Polinder, H.; Ferreira, J.A.; Zeilstra, D.; , “A fault tolerant drive for high speed permanent magnet machines," Power Electronics and Applications (EPE 2011), Proceedings of the 2011-14th European Conference on , vol., no., pp.1-10, Aug. 30 2011-Sept. 12011

16. Baran, M.E.; Teleke, S.; Bhattacharya, S.; , "Overcurrent Protection in DC Zonal Shipboard Power Systems using Solid State Protection Devices," Electric Ship Technologies Symposium, 2007. ESTS '07. IEEE, vol., no., pp.221-224, 21-23 May 2007

17. N. R. Mahajan, "System Protection for Power Electronic Building Block Based DC Distribution Systems," Ph.D. dissertation, North Carolina State University, November 2004, Available at: http://www.lib.ncsu.edu/theses/available/etd-12052004233822/unrestricted/etd.pdf.

18. Z. Xu, B. Zhang, S. Sirisukprasert, X. Zhou, and A. Huang, "The emitter turn-off thyristor-based DC circuit breaker," in Power Engineering Society Winter Meeting, 2002. IEEE, vol. 1, 2002, pp. 288-293.

19. C. Du, E. Agneholm, and G. Olsson, "VSC-HVDC system for industrial plants with onsite generators," Power Delivery, IEEE Transactions on, vol. 24, no. 3, pp. 1359-1366, July 2009

20. M. Bahrman, J. Johansson, and B. Nilsson, "Voltage source converter transmission technologies: the right fit for the application," in Power Engineering Society General Meeting, 2003, IEEE, vol. 3, July 2003, p. 4 vol. 2666.

21. L. Xu, B. Andersen, and P. Cartwright, "Multilevel-converter-based vsc transmission operating under fault ac conditions," Generation, Transmission and Distribution, IEE Proceedings-, vol. 152, no. 2, pp. 185-193, March 2005.

22. S. Kenzelmann, A. Rufer, D. Dujic, F. Canales, and Y. R. de Novaes, "A versatile dc/dc converter based on modular multilevel converter for energy collection and distribution,” in Renewable Power Generation 2011. IET International Conference on, Sept. 2011.

23. C. Davidson and D. Trainer, "Innovative concepts for hybrid multi-level converters for HVDC power transmission," in AC and DC Power Transmission, 2010. ACDC. 9th IET International Conference on, Oct. 2010, pp. 1-5.

24. G. Ding, G. Tang, Z. He, and M. Ding, "New technologies of voltage source converter VSC for HVDC transmission system based on VSC" in Power and Energy Society General Meeting - Conversion and Delivery of Electrical Energy in the 21st Century, 2008 IEEE, July 2008, pp. 1-8.

25. S. D. A. Fletcher, P. Norman, S. Galloway, and G. Burt, "Solid state circuit breakers enabling optimised protection of dc aircraft power systems," in Power Electronics and Applications (EPE 2011), 14 "European Conference on, Sept 2011.

26. S. D. A. Fletcher, P. Norman, P. Crolla, S. Galloway, and G. Burt, "Optimizing the Roles of Unit and Non-Unit Protection Methods within DC Microgrids" Accepted for IEEE Transactions on Smart Grids

Page 12 of 13 
27. P. J. Norman, S. J. Galloway, G. M. Burt, D. R. Trainer, and M. Hirst, "Transient analysis of the more-electric engine electrical power distribution network," in Power Electronics, Machines and Drives, 2008. PEMD 2008. 4th IET Conference on, April 2008, pp. 681-685.

28. ALSTOM, "Network protection and automation guide, chapter 10 unit protection of feeders. [online]," Available at: http://www.alstom.com/grid, [Accessed:29.5.12].

29. S. D. A. Fletcher, P. Norman, S. Galloway, P. Rakhra, G. Burt and V. Lowe, "Modeling and simulation enabled UAV electrical power system design" in SAE International Journal of Aerospace, vol. 4, no. 2, pp.1074-1083, November 2011

30. Ericsen, T.; Khersonsky, Y.; Schugart, P.; Steimer, P., "PEBB - power electronics building blocks, from concept to reality," Power Electronics, Machines and Drives, 2006. PEMD 2006. The 3rd IET International Conference on , vol., no., pp.12-16, 4-6 April 2006

\section{CONTACT INFORMATION}

Steven Fletcher, Research Assistant, University of Strathclyde, UK

steven.fletcher@eee.strath.ac.uk

\section{ACKNOWLEDGMENTS}

This work has been carried out as part of the Rolls-Royce UTC programme. 